\title{
Inverse Analysis Method on the Performance Evaluation of Geosynthetic Reinforcements in Highway Pavement on Expansive Soils
}

\author{
Debojit Sarker, ${ }^{1}$ and Jay X. Wang, Ph.D., P.E. ${ }^{2}$ \\ ${ }^{1} \mathrm{PhD}$ Candidate, Program of Civil Engineering, Louisiana Tech University, Ruston, LA 71272; \\ e-mail: dsa038@latech.edu \\ ${ }^{2}$ Professor, Programs of Civil Engineering and Construction Engineering Technology, Louisiana \\ Tech University, Ruston, LA 71272; e-mail: xwang@latech.edu
}

\begin{abstract}
Sometimes a pavement deflects only because of seasonal volume change of expansive soils in the pavement subgrade. Engineering practitioners expect an implementable and straightforward analysis method for a geosynthetic-reinforced pavement subjected to the swelling/shrinkage issue of expansive clayey subgrade, in an effort to find the bending moment, shear force and tension force distributions through the reinforced pavement, which are induced from the volumetric changes of subgrade soils. The virtual load method (VLM) was proposed in the past following the Timoshenko beam theory to analyze geosynthetic-reinforced pavement on expansive soils. In the VLM, the unknown virtual distributed load was obtained in the way by applying the inverse theory for the identification of material parameters of the pavementfoundation system. It was seen that the selection of the number of material parameters to obtain virtual load significantly affects the accuracy of the structural properties of the pavement and tensile properties of the geosynthetics if the linear least square method is used. In this paper, a unique numerical scheme was proposed in the hopes of solving the issue. After a forward problem was solved numerically, the Timoshenko beam deflection was taken as a start-up for the inverse problem to back analyze the load applied to the pavement. Solutions from forward/backward examples have explicitly shown the accuracy achieved related to the bending moment in the pavement and tension in the geosynthetic reinforcements. The proposed methodology can be applied for an in-depth understanding of the geosynthetic function for the mitigation of longitudinal cracks on pavements caused by heave/shrinkage of expansive soils.
\end{abstract}

\section{INTRODUCTION}

In the USA, billions of dollars are spent every year to resolve the swelling related distresses on the highways over expansive soils (Al-Qadi et al. 2009). It is typically not feasible to avoid these soils because of the widespread distribution everywhere all over the USA (Snethen 1979). Usually, these soils show volumetric change because of the presence of swelling mineral, e.g., montmorillonite that swells or shrinks with the fluctuation of moisture content (Chen 2012). The highways constructed over these expansive soils are subjected to differential movement with seasonal wetting and drying. They can cause heave or shrinkage, which results in the development of cracks that are found prevalently on the surface of the pavements (Nelson et al. 2015). A few mitigation approaches, including chemical stabilization, compaction, moisture barriers, and pre-wetting, were developed over time to overcome this issue (Khan et al. 2018; Lytton et al. 2005; Sarker et al. 2021; Sebesta 2002). However, these methods sometimes miss the mark because of the unpredictability of the issue and the excessive expense of 
implementation. Traditional chemical stabilization is financially reasonable up to a certain depth, while Ca-based stabilizers can lead to the formation of swelling minerals like ettringite within sight of sulfates (Chittoori et al. 2017; Puppala et al. 2018). As a solution to fix this segment of the highway, the authors proposed an adaptable mechanical system using geosynthetics that can moderate the uplift pressures from the expansive soils subgrade and protect the pavement surface.

Pavement structure is good in compression but weak in tension. Engineers added geosynthetics in layer to supplement this limitation of pavement. Significant research has been led to comprehend the effect of traffic loads on the performance of highways by incorporating geosynthetic within pavement layers (Perkins et al. 2005; Zornberg et al. 2017). However, performance measurement is not available to describe the effect of environmental loads (i.e., those resulting from subgrade volumetric changes) on highway performance. Many researchers have used characteristic models to simulate the behavior of reinforced pavement (Ghosh et al. 2017; Maheshwari et al. 2004; Shukla and Chandra 1994; Zhan and Yin 2001; Zhou et al. 2014). However, all these studies concentrated on a common forward problem. The analysis was performed at given external loads on the pavement, considered a reinforced Timoshenko beam, whose subgrade volume does not change significantly with variation in its moisture content. The Timoshenko beam theory cannot directly be applied for the case where deformation of geosynthetic-reinforced pavement is caused by the volume change of the subgrade, rather than a traffic load on the pavement.

Inverse problems in mechanics are formulated as a least-square output error minimization problem. In this research, viable strategies for both the forward and the inverse problems were described and numerically tested. The forward problem was formulated and solved by appropriate use of the boundary conditions combined with specialized algorithms. Effective implementation and parametrization of the structural analysis problem is a key issue for the development and testing of different techniques for the solution of the inverse problem (Stavroulakis 2013). Effective and automatic modeling and solution of geosynthetic-reinforced pavement on expansive soils for static loadings using boundary conditions were made for onedimensional elastic structures with nonlinear interaction effects. To understand the performance of geosynthetic reinforcements in the pavement on expansive soils, after a forward problem was solved numerically for static loadings, the beam deflection was taken as a start-up for the inverse problem to back analyze the virtual load applied to the pavement. The virtual load, which is to be determined using inverse theory, is expressed as a Fourier series and is the function of the model parameter vector essentially regarded as an array of material parameters of the geosyntheticreinforced pavement system. Once the model parameter vector is obtained, bending moments and shear forces in the pavement and tension in the geosynthetic layer can be calculated from the standard forward problem.

In this study, extensive computer implementation and parametric investigation of a numerical technique for the solution of the nonlinear least-squares problems which emerge during the investigation of the inverse (here the geosynthetic-reinforced pavement on expansive soils) problems have been performed. The optimization routines are either home-made programs or are taken from matrix analysis software packages (e.g., MATLAB). Numerical results demonstrate the performance of the applied strategies. 


\section{RESEARCH METHODOLOGY}

In the analytical model, the pavement geometry was considered as symmetric to the centerline, as appeared in Figure 1. The geosynthetic-reinforced pavement was simulated as a reinforced Timoshenko beam on an elastic foundation. Timoshenko beam theory is referred to as the firstorder shear deformation theory, which assumes that the transverse shear strain is consistent through the beam thickness. In this study, the Pasternak foundation model was adopted to simulate the subgrade soil because it considers the shear resistance of the reinforced pavement (Fwa et al. 1996). By adopting the Timoshenko beam theory to simulate pavement and the Pasternak model to simulate the foundation soil, we will be able to consider the effect of geosynthetic reinforcement. Finally, the inverse analysis will allow us to understand the mechanism of the initiation and propagation of the pavement cracks caused by heave or shrinkage of expansive soils subgrade.

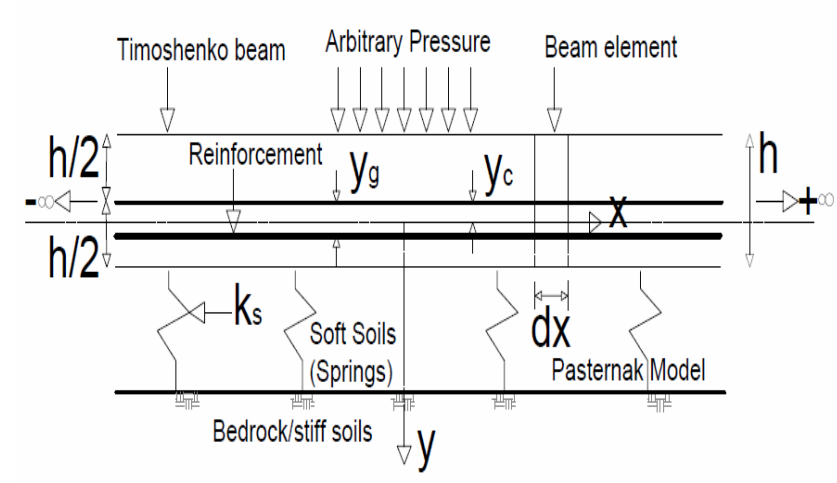

(a)

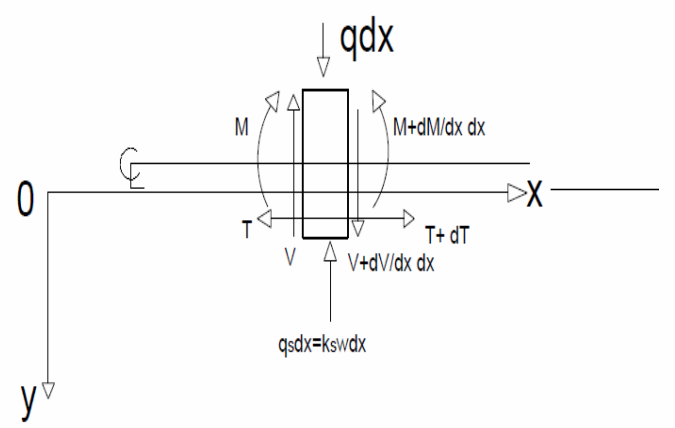

(b)

Figure 1. (a) Schematic diagram of 1-D loaded beam supported on elastic foundation, (b) Relations among loading, shear force, bending moment and tension (Sarker et al. 2019).

Analytical solution. Figure 1(a) shows the reinforcement in a Timoshenko beam resting on an elastic foundation. Two independent variables are settlement $w$ and rotation angle $\Phi$. Let us consider a finite beam with a beam length of $L$, bending stiffness $D$, and shear stiffness $C$. The relationship between moment $M$ and the rate of rotation angle change can be expressed as (Timoshenko 1921).

$$
M=-D \frac{d \Phi}{d x}
$$

Where $\Phi=$ rotation angle, and $D$ is the bending stiffness. The relationship between shear force $Q$ and shear deformation can be expressed as (Timoshenko 1921)

$$
Q=C\left(\frac{d w}{d x}-\Phi\right)
$$

Here, $C$ is the shear stiffness of the geosynthetic-reinforced beam.

The vertical force equilibrium of the beam element in Figure 1(b) leads to

$$
\frac{d Q}{d x}=k_{s} w-q
$$

Where $k_{s}$ is the spring constant in $\mathrm{kN} / \mathrm{m}^{3}$, and $q$ is the arbitrary pressure on the beam and may be a function of $x$. From the moment equilibrium of the beam element, we get 


$$
\frac{d M}{d x}=Q
$$

We take pressure $q$ as the self-weight, any type of external load, or the virtual load that produces equivalent deflection as the heave or shrinkage-induced vertical deformations on the pavement, acting across the length of the beam. Load $q$ can be expressed as a function of $x$, that is

$$
q=f(x) \text { for } 0<\mathrm{x}<\mathrm{L}
$$

Where $f(x)$ can be expressed as a Fourier cosine series.

$$
q=\sum_{n=0}^{\infty} A_{n} \cos \left(\frac{n \pi x}{L}\right)
$$

Using (1), (2), (3), (4), and (6), the governing differential equation for a reinforced Timoshenko beam on an elastic foundation can be expressed as (Wang et al. 2018; Yin 2000)

$$
D \frac{d^{4} w}{d x^{4}}-\frac{k_{s} D}{C} \frac{d^{2} w}{d x^{2}}+k_{s} w=\sum_{n=0}^{\infty} A_{n}\left[1+\frac{n \pi}{L} \frac{D}{C}\right] \cos \frac{n \pi x}{L}
$$

The shear stiffness $C$ can be expressed as (Cowper 1966)

$$
C=k G_{e} A
$$

Where $G_{e}$ is the equivalent shear modulus of the reinforced beam, here, $k$ is a reduction faction that depends on Poisson's ratio of the beam. Cross-sectional area $A$ for a unit width can be written as $A=1 \times h$. The reinforcement sheet, such as geotextile in the pavement, is not considered for shear force but usually is considered to take tension only. When reinforcement is considered taking shear force, the shear modulus $G_{e}$ for shear stiffness can be expressed as

$$
G_{e}=f(G)+f\left(G_{g}\right) \frac{A_{g}}{A}
$$

Where $G, G_{g}$, and $A_{g}$ are the shear modulus of the beam, shear modulus of the reinforcement, and cross-sectional area of the reinforcement, respectively. Yin showed that reinforcement tensile force $\mathrm{T}$ could be expressed as (Yin 2000)

$$
T=-E_{g}\left(y_{g}-y_{c}\right) \frac{d \Phi}{d x}
$$

Here, $E_{g}, y_{g}$, and $y_{c}$ are Young's modulus of the reinforcement, location of reinforcement, and location of the neutral line.

Eq. 7 is the fourth-order nonhomogeneous linear differential equation. By solving Eq. 7, we can get the beam deflection $w$ in terms of Fourier constant $A_{n}$. The solution of the differential equation is the summation of a homogeneous solution of the beam for any type of loading, e.g., a distributed load and a particular solution, which is the function of that load type. After obtaining the general solution for beam deflection $w$, we can obtain the equation for rotation $\Phi$ using Eqs. (1), (2), and (3), (4). Then, the equation of rate of rotation can be obtained to get the equation of bending moment and shear force using Eqs. 1 and 4, respectively.

Applying boundary conditions $\left.M\right|_{x=0}=0,\left.Q\right|_{x=0}=0,\left.M\right|_{x=L}=0$, and $\left.Q\right|_{x=L}=0$ to the equations of bending moment, and shear force, they can be written in the matrix form $[M]\{c\}=$ $[R]$. Where, $\{c\}=\left[C_{1} C_{2} C_{3} C_{4}\right]^{\prime}$, represents the four integral constants to be determined from the stated boundary conditions. Matrix $\mathbf{M}$ is a function of basic parameters such as $\alpha, \beta, L, k_{s}, D$, $I$, and $C$, while $\mathbf{R}$ is a function of parameters for load $q$ (e.g., $\left[\begin{array}{llll}a_{1} & a_{2} & \ldots & a_{n}\end{array}\right]$ ). Here, $\alpha$ and $\beta$ are the characteristics of the system, and $I$ is the moment of inertia of the beam. Following the similar mathematical manipulation done by Khan and Wang (2017), the general solution for deflection $w$ 
can be reduced into a set of a linear combination of equations. Eq. 11 shows the final matrix solution of the beam deflection. Here, matrix element $\mathbf{H}_{\mathbf{n}}$ is a function of basic parameters such as $\alpha, \beta, L, k_{s}, D, I$, and $C$.

$$
[w(x)]=\left[\frac{1}{k_{s}} H_{1} H_{2} \ldots H_{n}\right]\left[\begin{array}{c}
A_{0} \\
a_{1} \\
a_{2} \\
\vdots \\
a_{n}
\end{array}\right]
$$

A set of heave or shrinkage-induced vertical displacements caused by expansive soil subgrade indicated by $w_{P}$ can be predicted based on the unsaturated soil mechanics or directly measured in the field. It is regarded as the observed output for the inverse problem. The calculated pavement (here, beam) deflection can be taken as $w_{B}$. The observation data can be related to the model estimated values at the predetermined points can be expressed by the following relationship

$$
w_{P}=w_{B}(X \mid \zeta)+\varepsilon
$$

Where $\mathbf{X}$ represents the known input matrix.

$$
X=\left(\chi_{i j}\right) \in \mathbb{R}^{m \times(n+1)}
$$

Here, matrix element $\chi$ is dependent on parameters such as $\alpha, \beta, L, k_{s}, D, I$, and $C$.

Model parameter vector, $\zeta=\left[\begin{array}{c}A_{0} \\ a_{1} \\ a_{2} \\ \vdots \\ a_{n}\end{array}\right]$

And, $\varepsilon$ is the error vector.

Here, the linear least square method is used, and the algebraic solution of the ordinary equation can be written as (Khan et al. 2020; Sarker et al. 2019)

$$
\zeta=\left(\chi^{T} \chi\right)^{-1} \chi^{T} w_{P}
$$

Once $\zeta$ is found, using Eq. 11, we can calculate the beam deflection produced by the virtual load along the cross-section of the pavement. Then, $\zeta$ can be used to obtain all the Fourier constants, and by employing Fourier constants in Eq. 6, we can obtain the virtual load imposed on the pavement caused by deflection $w_{P}$. After that, using matrix $\{c\}=[M]^{-1}[R]$, all the integral constants can be obtained. Finally, all the parameters will be identified; thus, rotation, moment, and shear force of the pavement and tensile force of the geosynthetic at any crosssection of the beam can be obtained. It was found that the selection of the number of the Fourier terms for the virtual load significantly affects the convergence of the bending moment on the pavement and tension imposed on geosynthetics when the linear least square method is used. The authors propose the following relationship to overcome the convergence issue.

$$
m=\frac{L}{\Delta x} \approx n+1
$$

\section{PARAMETRIC STUDY}

In this study, the geosynthetic-reinforced pavement is investigated. It is simplified as a reinforced Timoshenko beam on an elastic foundation. Parametric studies were performed by selecting a group of parameters, as given in Table 1, obtained from previous literature. These 
parametric studies will allow engineering practitioners to select different parameters of the pavement-foundation system for evaluation, define the parameter range, specify the design constraints, and analyze the results of each parameter variation.

This study highlights the selection of the number of Fourier terms for the virtual load, which is regarded as an array of material parameters of the geosynthetic-reinforced pavement system. Additionally, the effect of shear stiffness of geosynthetic reinforcements is discussed to evaluate the performance of different types of geosynthetics. Distributions of bending moment and shear force through the reinforced pavement due to variation in geosynthetic shear stiffness are also presented. The structural properties, as defined in Table 1, were obtained from literature to compare the deflection calculated in this study. The Young's modulus $E$ is taken to be 50,000 $\mathrm{kPa}$. Researchers have investigated the applicability and reliability of spring constant $k_{s}$, which is known as modulus of subgrade reaction and can be determined using simplified empirical equations (Selvadurai 2013; Terzaghi 1955).

Table 1. Dimensions and properties of the pavement-foundation system.

\begin{tabular}{l|c|l|c}
\hline \multicolumn{1}{c|}{ Properties } & Value & \multicolumn{1}{|c}{ Properties } & Value \\
\hline $\begin{array}{l}\text { Length of the pavement, } \mathrm{L}(\mathrm{m}) \\
\begin{array}{l}\text { Thickness of the pavement, } \mathrm{h} \\
(\mathrm{m})\end{array}\end{array}$ & 3 & $\begin{array}{l}\text { Bending stiffness, D }(\mathrm{kN}-\mathrm{m}) \\
\text { Shear stiffness, C }(\mathrm{kN} / \mathrm{m})\end{array}$ & $2,216.2$ \\
Load, q0 $(\mathrm{kPa})$ & 1,000 & $\begin{array}{l}\left.\text { (Full } \mathrm{G}_{\mathrm{g}}\right) \\
\text { Shear stiffness, C }(\mathrm{kN} / \mathrm{m}) \\
\left(\text { Zero } \mathrm{G}_{\mathrm{g}}\right)\end{array}$ & $26,797.4$ \\
$\begin{array}{l}\text { Modulus of subgrade reaction, } \\
k_{x}\left(\mathrm{kN} / \mathrm{m}^{3}\right)\end{array}$ & 21,978 & $\begin{array}{l}\text { Location of the geosynthetic, } \\
\mathrm{yg}_{\mathrm{g}}(\mathrm{m})\end{array}$ & 0.24 \\
\hline \hline
\end{tabular}

Table source: Yin (2000).

As a validation for the inverse method, the external loads from the forward method and the virtual load computed from the inverse method were plotted and compared. Figure 2 shows the deflection of the geosynthetic-reinforced pavement caused by a predetermined load applied on the pavement and the deflection caused by the virtual load. In the forward analysis, the deflection was caused by external load and plotted as "Wb_FDM". On the other hand, in the inverse analysis, the deflection was caused by the virtual load when deflection data obtained from the forward analysis was taken as input and plotted as "Wb_LLS". The maximum deflection caused by external load was obtained by $3.73 \mathrm{~mm}$ while taking this deflection data as input in the inverse model produces a virtual load that causes maximum deflection of $3.50 \mathrm{~mm}$. The percent error between "Wb_FDM" and "Wb_LLS" was 6.2\%. However, percent error could be reduced by increasing the number of Fourier terms as the first five terms of Fourier constants were considered in this case for inverse analysis.

Loading, Shear force, and bending moment distribution along the geosynthetic-reinforced pavement cross-section resulted from forward and inverse analysis methods that were plotted in Figures-3, 4, and 5, respectively. It can be observed from Figure 3 that the computed virtual load gets closer to the external load when the number of Fourier terms is increased. In Figures 4 and 5, "FDM" represent the results obtained from the forward analysis or due to applied external load on the pavement. In comparison, "LLS" represent the results obtained from the inverse 
analysis or due to virtual load. Shear forces and bending moments were calculated for different Fourier terms such as 4, 8, 15, and 100. It can be observed from Figure 5 that the number of Fourier terms for the virtual load significantly affects the convergence of the bending moments at the beam (here, pavement) boundary when the linear least square method (LLS) is used. Using $\Delta \mathrm{x}=0.03$ in Eq. 15, it can be observed from Figure 5 that, for 100 Fourier terms the bending moment distribution converges well.

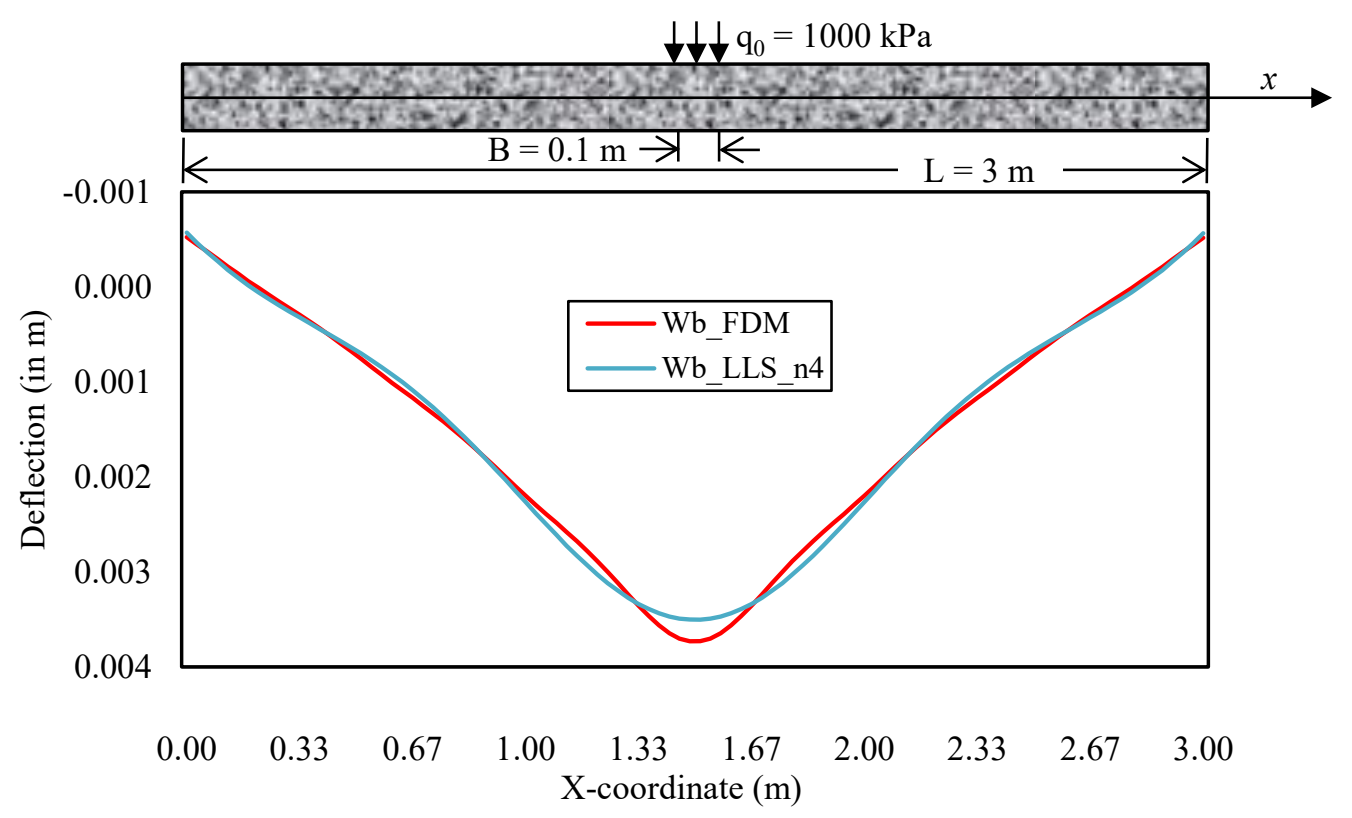

Figure 2. Deflection along the cross-section of the reinforced pavement.

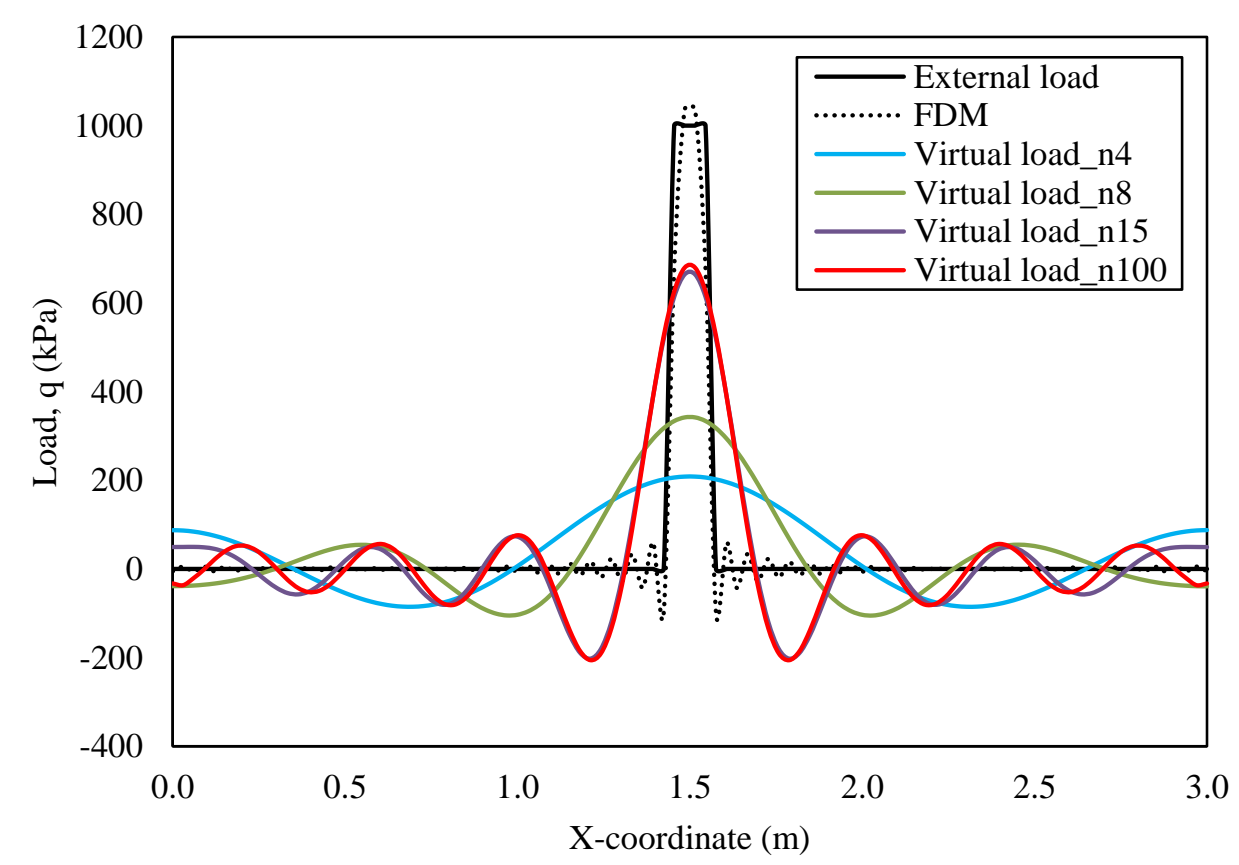

Figure 3. Load distribution along the cross-section of the reinforced pavement. 


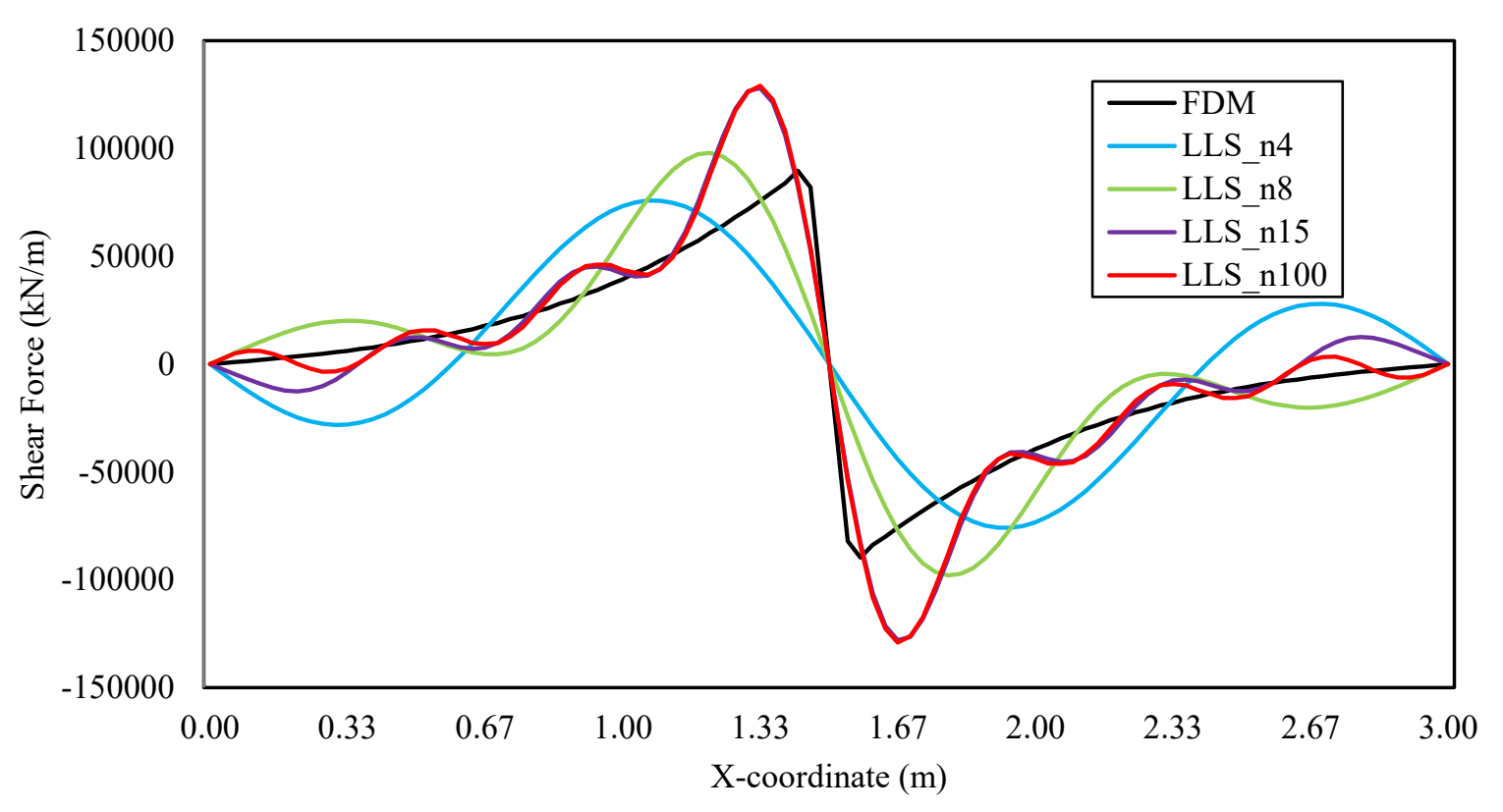

Figure 4. Shear force distribution along the cross-section of the reinforced pavement.

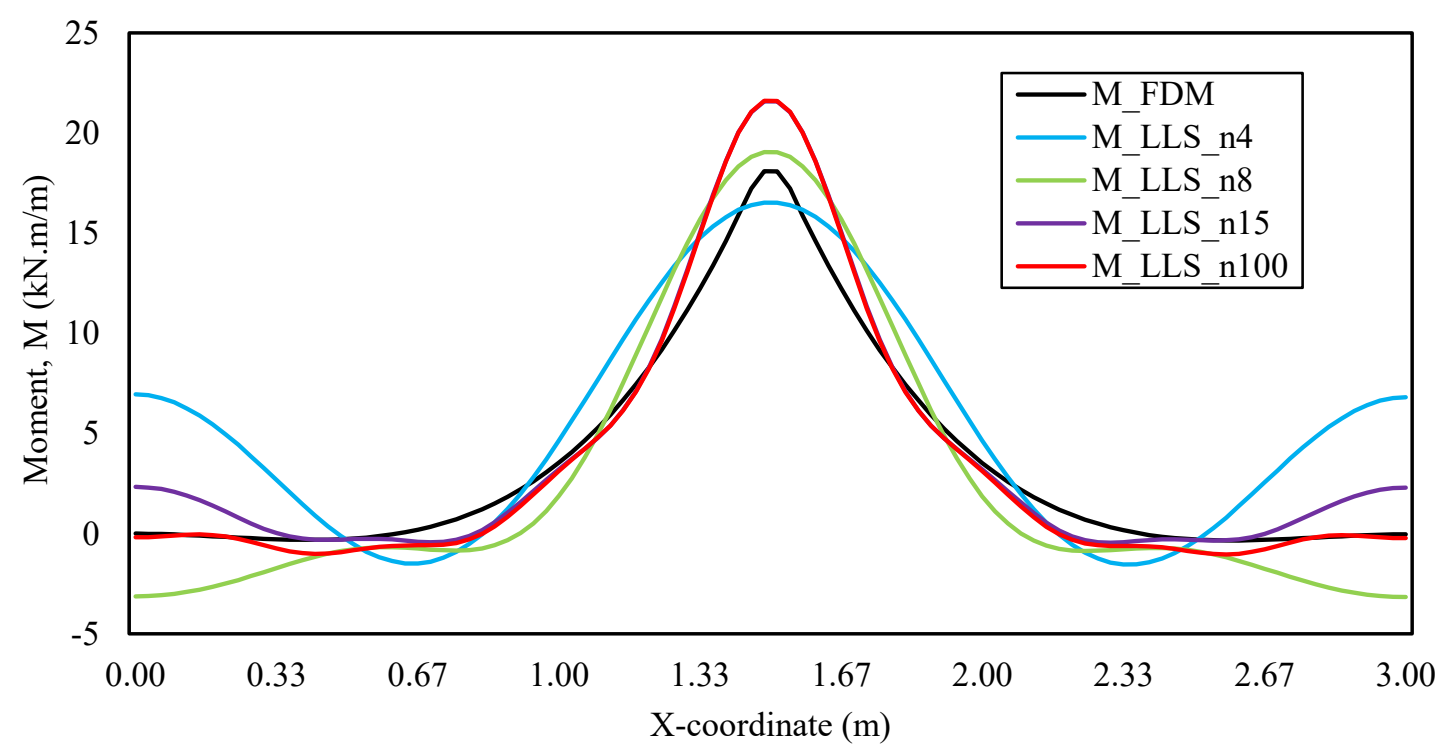

Figure 5. Moment distribution along the cross-section of the reinforced pavement.

The effects of geosynthetic shear stiffness $G_{g}$ were investigated in this parametric study research, and different outcomes were plotted in Figure 6. Typically, geotextiles are not considered to take shear force but tension only. The geosynthetic shear stiffness $G_{g}$ was assumed to be zero for this case and plotted as "Zero Gg" (see Figure 6). Then again, geogrid sheets may be considered to take shear force in addition to tensile force. So, for the geogrid case, their shear stiffness was fully considered and plotted as "Full $\mathrm{Gg}$ " in Figure 6 as well. 


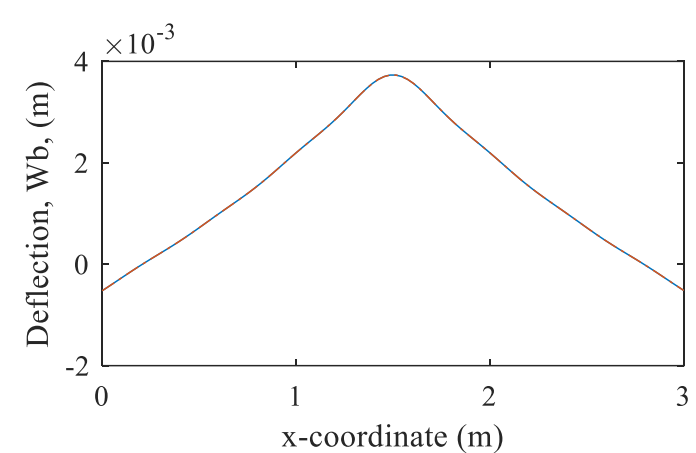

(a)

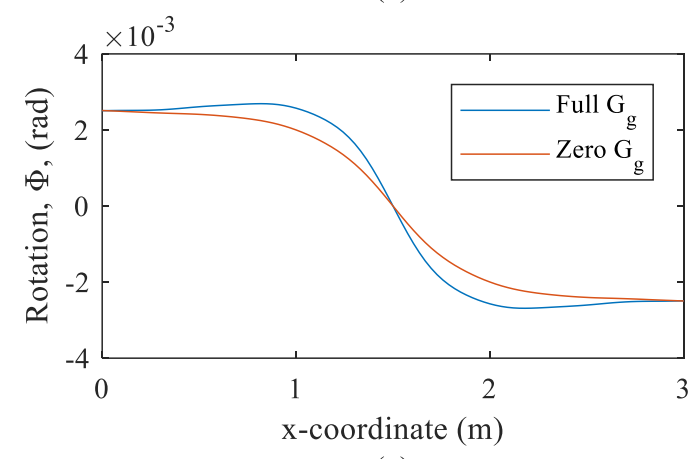

(c)

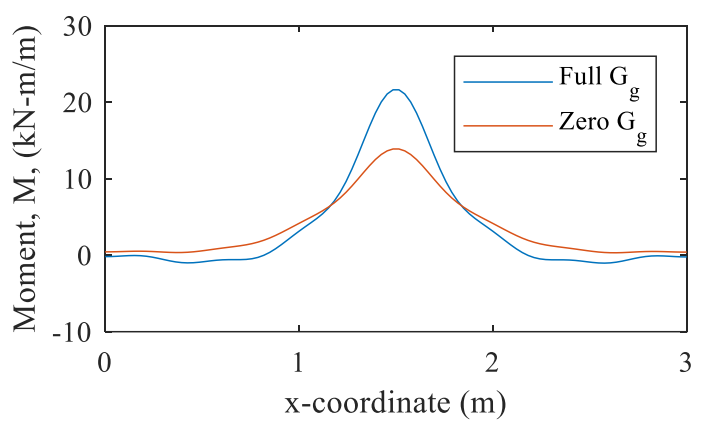

(e)

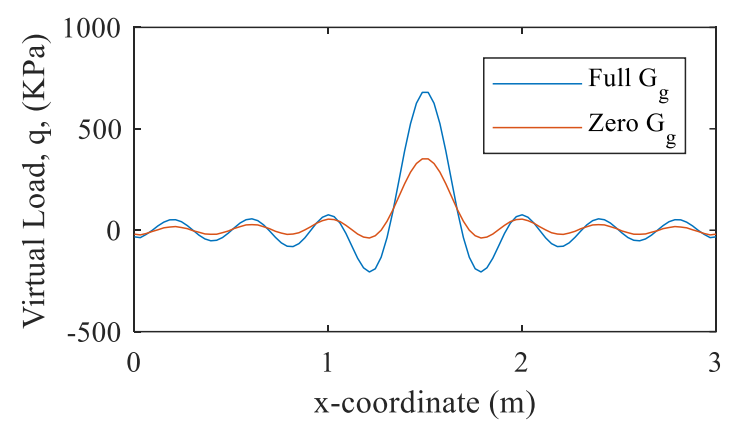

(b)

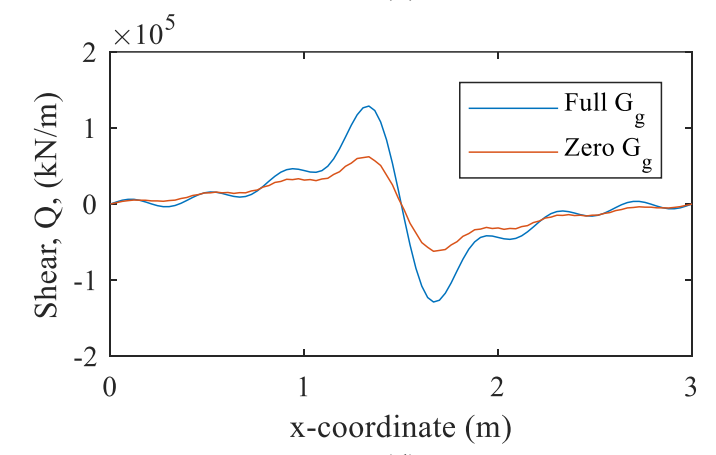

(d)

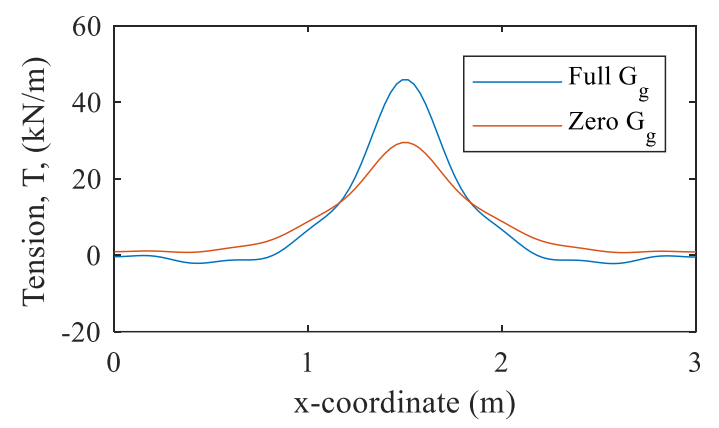

(f)

\section{Figure 6. (a) Deflections, (b)Virtual load, (c) Rotation, (d) Shear force, and (e) Bending moment distribution in the pavement, and (f) Tension in the geosynthetic reinforcements.}

As indicated above, in the inverse method, performance analyses of a geosyntheticreinforced pavement on expansive soils requires the input of deformation of the subgrade in the formulations. Researchers investigated field moisture content and soil suction potentials of expansive subgrades and identified the potentials at which soil and pavement cracking occur (Ahmed et al. 2018; Fernandes et al. 2015; Puppala et al. 2012; Sarker and Wang 2021; Zornberg et al. 2010). Numerous methods have been proposed to calculate heave or shrinkage of the expansive soils from moisture content variations. The virtual distributed load causes geosynthetic-reinforced pavement deflection equivalent to heave or shrinkage-induced deformations of the subgrade. As an example of the geosynthetic-reinforced pavement on elastic foundation model, a forward problem was solved numerically for an external load of $1000 \mathrm{kPa}$. To demonstrate the performance evaluation of geosynthetic reinforcements in pavement on expansive soils, the Timoshenko beam deflection was taken as input for the inverse problem to 
back-calculate the load applied to the pavement. Virtual loads, rotations, shear forces and bending moment on the cross-sections, and tensile forces through the geosynthetic reinforcement along the pavement width direction are plotted in Figure 6. The critical values of shear force and bending moment on pavement and tension forces through the geosynthetics can be obtained from Figure 6.

Results with the condition of Zero Gg are for the geotextile condition, and Full Gg is for the geogrid condition. From Figure 6(a), it can be observed that the calculated Timoshenko beam deflections from the virtual loads agreed well with the results obtained from the forward analysis. Figure 6(b) shows the increase in virtual load is about $48 \%$ for the geogrid-reinforced pavement section compared to the geotextile-reinforced section. It is interesting to indicate that geogrid-reinforced pavement could take a much greater load than geotextile-reinforced pavement under the same deflection condition caused by the heave/shrinkage of expansive subgrade soils. It is found that, for the geogrid-reinforced pavement, the maximum shear force was $52 \%$ higher than that for the geotextile-reinforced pavement, the maximum bending moment $36 \%$ higher, and the maximum tension force $37 \%$ higher. It can be presumed that the geosynthetic-reinforced pavement deflection initiated from subgrade (e.g. volume change of expansive soils) may resist more shear force or bending moment when the geosynthetic shear stiffness is considered. The tension without considering geosynthetic shear stiffness is smaller than the case where geosynthetic shear stiffness is considered.

\section{CONCLUSION}

In this research, an inverse-based analytical model was proposed to evaluate the structural performance of geosynthetic reinforcements in the pavement on expansive soils following the Timoshenko beam theory by incorporating the volume change of subgrade in formulations. A practical, robust, and rapid method for the solution of inverse problems associated with geosynthetic-reinforced pavement on expansive soils was being developed. Numerical results have shown the efficiency of the proposed model to overcome the convergence problem related to bending moment on the pavement and tension on geosynthetic reinforcements. The effects of geogrid and geotextile reinforcement on the performance of pavement on expansive soils were investigated. The study suggests the superior performance of geogrid over geotextile to moderate the uplift pressure from the expansive soils subgrade for protecting the pavement surface. Nevertheless, the method does appear promising and, given data of sufficient precision, will allow for substantial new developments in the geosynthetic industry. This study will allow the geotechnical and pavement engineers to design the geosynthetic-reinforced pavement on expansive soils by integrating volume change-induced deformations of the subgrade in the model.

\section{ACKNOWLEDGEMENT}

This work was supported by the Geosynthetic Institute with a 2020-21 GSI Fellowship grant under contract No. 32-4116-65048 at Louisiana Tech University.

\section{REFERENCES}

Ahmed, A., Hossain, M. S., Bin Alam, M. J., and Khan, M. S. (2018). "Moisture and Matric 
Suction Behavior in Unsaturated Subgrade through Field Instrumentation and Numerical Modeling." PanAm Unsaturated Soils 2017, American Society of Civil Engineers, Reston, VA, 226-235.

Al-Qadi, I. L., Buttlar, W., Baek, J., and Kim, M. (2009). Cost-effectiveness and performance of overlay systems in Illinois volume 1: effectiveness assessment of HMA overlay interlayer systems used to retard reflective cracking. Illinois Center for Transportation (ICT).

Chen, F. H. (2012). Foundations on Expansive Soils. Elsevier.

Chittoori, B., Tamim, M. M., Gajurel, A., and Mishra, D. (2017). "Evaluating the ability of swell prediction models to predict the swell behavior of excessively high plastic soils." PanAm Unsaturated Soils 2017, 177-189.

Cowper, G. R. (1966). “The Shear Coefficient in Timoshenko's Beam Theory.” Journal of Applied Mechanics, 33(2), 335.

Fernandes, M., Denis, A., Fabre, R., Lataste, J.-F., and Chrétien, M. (2015). "In situ study of the shrinkage-swelling of a clay soil over several cycles of drought-rewetting." Engineering Geology, 192, 63-75.

Fwa, T. F., Shi, X. P., and Tan, S. A. (1996). "Use of Pasternak foundation model in concrete pavement analysis." Journal of transportation engineering, American Society of Civil Engineers, 122(4), 323-328.

Ghosh, B., Fatahi, B., Khabbaz, H., and Yin, J.-H. (2017). “Analytical study for double-layer geosynthetic reinforced load transfer platform on column improved soft soil." Geotextiles and Geomembranes, Elsevier, 45(5), 508-536.

Khan, M. A., and Wang, J. W. (2017). "Application of Euler-Bernoulli Beam on Winkler Foundation for Highway Pavement on Expansive Soils.” Proc., PanAm-UNSAT 2017: Second Pan-American Conference on Unsaturated Soils, ASCE. (Accepted).

Khan, M. A., Wang, J. X., and Sarker, D. (2018). "Stabilization of Highly Expansive Moreland Clay Using Class-C Fly Ash Geopolymer (CFAG)." IFCEE 2018, American Society of Civil Engineers, Reston, VA, 505-518.

Khan, M. A., Wang, J. X., and Sarker, D. (2020). "Development of Analytic Method for Computing Expansive Soil-Induced Stresses in Highway Pavement." International Journal of Geomechanics, 20(2).

Lytton, R., Aubeny, C., and Bulut, R. (2005). Design procedure for pavements on expansive soils. Texas Transportation Institute, Texas A \& M University System.

Maheshwari, P., Basudhar, P. K., and Chandra, S. (2004). "Analysis of beams on reinforced granular beds." Geosynthetics International, 11(6), 470-480.

Nelson, J. D., Chao, K. C., Overton, D. D., and Nelson, E. J. (2015). Foundation Engineering for Expansive Soils. Wiley Online Library.

Perkins, S. W., Bowders, J. J., Christopher, B. R., and Berg, R. R. (2005). "Geosynthetic reinforcement for pavement systems: US perspectives." International Perspectives on Soil Reinforcement Applications, 1-13.

Puppala, A. J., Manosuthkij, T., Nazarian, S., Hoyos, L. R., and Chittoori, B. (2012). "In situ matric suction and moisture content measurements in expansive clay during seasonal fluctuations." Geotechnical Testing Journal, ASTM International, 35(1), 74-82.

Puppala, A. J., Talluri, N., Congress, S. S. C., and Gaily, A. (2018). "Ettringite induced heaving in stabilized high sulfate soils." Innovative Infrastructure Solutions, Springer, 3(1), 72.

Sarker, D., Apu, O. S., Kumar, N., Wang, J. X., and Lynam, J. G. (2021). “Application of Sustainable Lignin Stabilized Expansive Soils in Highway Subgrade.” International 
Foundations Congress \& Equipment Expo (IFCEE 2021), (Accepted), Dallas, TX.

Sarker, D., and Wang, J. X. (2021). "Experimental Study on Soil Water Retention Properties of Compacted Expansive Clay." 4th International Conference on Transportation Geotechnics (ICTG 2021), (Accepted), Chicago, IL.

Sarker, D., Wang, J. X., and Khan, M. A. (2019). "Development of the Virtual Load Method by Applying the Inverse Theory for the Analysis of Geosynthetic-Reinforced Pavement on Expansive Soils." Geo-Congress 2019: Geotechnical Materials, Modeling, and Testing, American Society of Civil Engineers, Reston, VA, 326-339.

Sebesta, S. (2002). Investigation of maintenance base repairs over expansive soils: Year 1 report. Texas Transportation Institute, Texas A \& M University System.

Selvadurai, A. P. S. (2013). Elastic analysis of soil-foundation interaction. Elsevier.

Shukla, S. K., and Chandra, S. (1994). "A generalized mechanical model for geosyntheticreinforced foundation soil." Geotextiles and Geomembranes, 13(12), 813-825.

Snethen, D. R. (1979). Technical guidelines for expansive soils in highway subgrades.

Stavroulakis, G. E. (2013). Inverse and crack identification problems in engineering mechanics. Springer Science \& Business Media.

Terzaghi, K. (1955). "Evaluation of Coefficient of Subgrade Reaction." Geotechnique, London, 5(4), 41-50.

Timoshenko, S. P. (1921). "LXVI. On the correction for shear of the differential equation for transverse vibrations of prismatic bars." The London, Edinburgh, and Dublin Philosophical Magazine and Journal of Science, Taylor \& Francis, 41(245), 744-746.

Wang, J. X., Sarker, D., and Ikra, B. (2018). Development of a Mechanistic-based Design Method for Geosynthetic-Reinforced Pavement on Expansive Soils and Prediction of Moisture Content Fluctuations in Subgrades. Southern Plain Transportation Center, Norman, OK.

Yin, J.-H. (2000). "Closed-Form Solution for Reinforced Timoshenko Beam on Elastic Foundation.” Journal of Engineering Mechanics, 126(8), 868-874.

Zhan, C., and Yin, J. H. (2001). "Elastic Analysis of Soil-Geosynthetic Interaction." Geosynthetics International, 8(1), 27-48.

Zhou, W.-H., Zhao, L.-S., and Li, X.-B. (2014). "Analytical study for geosynthetic reinforced embankment on elastic foundation." Ground Improvement and Geosynthetics, 444-451.

Zornberg, J. G., Gupta, R., and Ferreira, J. A. Z. (2010). "Field performance of geosynthetic reinforced pavements over expansive clay subgrades." 9th International Conference on Geosynthetics, Guarujá, Brazil, 1481-1484.

Zornberg, J. G., Roodi, G. H., and Gupta, R. (2017). "Stiffness of Soil-Geosynthetic Composite under Small Displacements: I. Model Development.” Journal of Geotechnical and Geoenvironmental Engineering, 143(10), 04017075. 